\title{
A NEW PARADIGM FOR INFORMATION SECURITY EDUCATION AT DOCTORAL LEVEL
}

\author{
Nimal Jayaratna \\ Curtin University of Technology, GPO Box U1987, Perth, Western Australia, 6845 Australia
}

\begin{abstract}
The Information Security is one of the fastest growing research areas in the field of Computer science and Information Technology/Systems. However, if research into security is to be successful, then researchers' mindsets have to match and exceed those who engage in intrusive, unlawful and unethical activities in the field of Information Systems and Technology. Security Professionals and for that matter those engaged in research and security product/service development need to be able to 'think like the criminals but not act like them'. Such a task is extremely difficult because unlike criminals/terrorists, Security Professionals thinking is highly conditioned by regulations, law, rules, procedures, documentation, policies, values ethics, and concern for the consequences of undesirable action on those affected. There is of course the danger that if you follow the criminal ways of thinking then you may become tempted to follow their behavior eventually. So, how can the mindsets be trained to enable Security Professionals to think freely without necessarily having to go through experience based learning! How can we develop doctoral programs that specifically target the development of the conceptual mindsets of the researchers! What specific sets of concepts will be useful for addressing these issues! These are questions that will be addressed in this paper.
\end{abstract}

Key words: IT security education, doctoral programs. 


\section{INTRODUCTION}

Criminals and Terrorists' mindsets are guided by misplaced creativity and innovation. That creativity comes naturally to them as they consciously or unconsciously decide to take no regard for procedures policies, regulations, rules, the law or concerns for others while those who abide by those behavioral guidelines are constrained in their thinking. This creates a huge disadvantage for Security Personnel as they are forever engaged in detection and recovery as their primary mode of learning. Some alternative ways of thinking have to be encouraged among Security Professionals. Doctoral programs that plan to develop Security Professionals skills need to deliberate target the development of their conceptual mindsets if they are to prepare them for the difficult tasks of preventing, detecting and recovering aspects of socially valued legal activities. This is a task that has been undertaken by the use of 'Systems' philosophy and concepts (Ackoff 1971) for many years.

'Systems' are simply an holistic way of understanding real world phenomena. Systems concepts help to focus people's minds on the interconnections of parts before the study of the individual parts. In essence, systems concepts help us to understand the nature of the interconnections required to achieve the outcome and behavior of an entity (Ackoff 1972). Systems concepts and philosophy have been around for thousands of years. For example the systems phrase 'A whole is greater than the sum of its parts' has been attributed to Aristotle. These concepts were revived in the 60s to help address the much required integrative aspects of knowledge, skills, and the design/development of objects, products and services (Katz and Khan 1966). If so what new paradigmatic shift is necessary for those engaged in doctoral research into information security issues?

Systems concepts that are discussed in the literature and applied in practice since the 60s take what Checkland (1999) defines as a 'hard' systems view (Katz and Rosenzwig 1970). That is those who use 'systems' in this sense take the world to contain 'systems' i.e. 'taken-as-given' systems - see Checkland for a rich account of the shift from Science to Systems way of thinking in problem solving. In this way researchers and practitioners have been able to take a much wider and holistic view of the situations than before and develop better and more effective solutions that focus on integration to produce the desirable results. The use of systems notions in this way of thinking is to describe the world in systems terms e.g. education systems, transport systems, security systems. We name this as the use of 
'systems' in ontological mode meaning that knowledge about systems are not subject to question.

The paradigmatic shift that is advocated in this paper is one of mode rather than the nature of the concepts. We name this new paradigm shift as 'systems epistemology'. In this mode Checkland (1999) considers the enquiry of the world to be assisted by 'systems' notions rather than consider the world itself as consisting of systems. He classifies this as 'soft' systems thinking. In arguing for this richer and a more powerful mode of enquiry, Checkland (1999, A11) conceives the enquirer's role as one of 'I spy complexity and confusion; but I can organize exploration of it as a learning system'. Churchman (1971) in his famous book on 'The Design of Enquiring Systems' also illustrated similar mode of enquiry of the world using different philosophical notions each of which yields a different perception of reality. Vickers (1968) called this mode of thinking as 'Appreciative Systems'. These are schemata formed within the mindsets that help to make sense of some part of reality but not others.

'Whatever the mind can represent to itself, from a cow to a contract, from a law of nature to a legal principle, is recognized by applying schemata - "readiness to see" which are themselves developed or restricted, confirmed or confused, elaborated or simplified, by further use....... This circular process, which contains the real answer to all conundrums of "hen-and-egg" type, is ubiquitous through the whole range of learning. It is the commonest fact of life - and the first foundation for a scientific epistemology' (Vickers 1968, p193-194).

All three authors have been trying to shift enquirers' attention away from things-out-there in the world to thinking about the ways of conceptualizing meaning of the things-out-there and discuss the nature of the frames of references for use in that structuring processes.

Let's contrast these two different modes of using the same 'systemic' concepts in order to appreciate the power of the paradigm shift for doctoral education. 


\section{Ontological Mode}

Attention is to discover the 'system' out there in the world to be modeled and changed. Systems have existence without us and can therefore be named and observed.

The process of boundary construction is implicit or unconscious. Because of this any changes that are undertaken to boundary position tends to be either defended as a challenge to personal status or position or accepted as part of political process of accommodation.

Select phenomena in the world to match the 'systems' characteristics that are carried in the mind set.

Locked into the 'systems' boundary. The boundary separates the system and its environment and therefore the enquirer's attention is on those inputs and outputs that cross the boundary.

Focus is on the re-arrangement and the modification of the systems' content. The boundary is not open to question.

\section{Epistemological Mode}

Attention is to question 'Why I should consider the chosen set of observed phenomena as a 'system'? Systems don't have no existence without an observer.

The process of boundary construction is explicit or conscious. Questions to the boundary position is encouraged and pursued. The wish is to ensure that the boundary position is relevant and useful and the interest is to discover the rationale for the views.

Evaluate the phenomena in the world for their potential for inclusion in the modeling using 'systems' ideas.

Since the boundary is an artificial construct, a system and its environment construction are subjective. The inputs and outputs will depend on the boundary position.

Focus is on the relevance of the chosen boundary and its systems' context. Question is whether relevant elements have been included. 
Ontological Mode continued

In general, the mapping of 'systems' is a one-off activity. This is confirmed by the phrases 'I found the system', 'the system is', 'the problem with the system', 'I designed the system', etc.

Since the system is established, any subsequent questions that challenge the boundary of the system are rejected. Questions are seen as a challenge to authority, status and position. The reactions are expressed by emotional rejection or as political denial.

Skills used are for the transformation of the content of the system. Enquirers are preoccupied with re-design or construction.
Epistemological Mode continued

In general, the mapping is a continuous set of activities. There is never the system as it is an artificial selection of a set of related phenomena for exploration.

Since the relevance and validity of a system is never established, there is continuous seeking of information to confirm the status of its relevance. Neither emotions nor politics have a part to play in this mode of logical analysis.

Skills used are for the examination of the context of the chosen 'system'. Enquirers are interested in establishing the justification for the design.

\section{EPISTEMOLOGICAL AND ONTOLOGICAL MODES OF THINKING AND SECURITY}

In the epistemological mode of thinking, there are no absolute 'systems' in the world. What may exist is a selected sets of perceptions about the world which we may justify as 'systems' using a set of systemic characteristics as the basis for making that selection. In that sense, the choice of 'systems' is a deliberate and a conscious intellectual activity (Jayaratna 1994). This means that 'systems' has no existence outside the observer/enquirer. Since 'systems' do not exist without an enquirer then it makes sense to concentrate more on the role of 'systems' on the mindset of the Security Personnel than on the technology, objects or physical aspects of security issues. This is the same philosophy that has been used for underpinning the design of the 
Masters Program in Internet Security Management curriculum (Armstrong and Jayaratna 2002).

As discussed earlier, criminals naturally think outside the box while we, through our childhood training, secondary and university education and work experience together with other conditioning factors such as values, procedures, policies, law, regulations, values, ethics and our concern for others of our actions tend to think within strong boundaries. These boundaries constrain our ability to become creative and innovative. Since it is difficult and also raises ethical and value issues for learning to think like a criminal, we have to find other ways of freeing the minds of the Security personnel. We believe that the same level and ways of learning to think can be achieved through the use of epistemological notions of 'systems' as discussed in Checkland (1981), Churchman (1971) and Vickers (1968). This way of conceptualizing security breaches across boundaries, free the researchers to think of security boundaries as artificially constructed devices that could be placed anywhere, not necessarily at the level physical layout of buildings, hardware networks, groups etc. Equally the freedom, to construct 'systems' in their mindsets, enables doctoral students to be more creative and innovative in their research. They are better able to organize the knowledge thus gained. As Checkland humorously puts it 'A cat can be considered as part of a mouse eliminating system'. Indeed it can also be considered as part of: a home entertainment system; a friendship network system; affectionate generating system; or a child substitution system. Pursued in this way, doctoral students are able to pursue their methods of enquiry and solutions in many novel ways.

The conceptual closure of a 'system' from its environment does not necessarily insulate us from the observed or non-observed phenomena in the world. The boundary is artificial and therefore is permeable and that is the reason why the enquirer needs to become open on a continuous basis for external feed back and information that help them to adjust or shift those boundaries. This ability to conceptualise and re-conceptualise systems boundaries is critical for Security Personnel thinking processes as they have to continuously match or anticipate the actions of the criminals/terrorists.

For example, the ontological mode of systems thinking makes the Security Personnel focus on inputs and outputs at fixed points e.g. entry to the building, network access, while the epistemological mode of 'systems' thinking enables them to draw boundaries anywhere and at any level. Each re-drawing will highlight a different set of security related inputs and outputs. 
Doctoral programs that are intended to generate knowledge for industry use therefore need to include the preparation of the intellectual mindset of their students to a very high and deep level. Students need to be exposed to many different philosophical ways of understanding phenomena. Most essentially, they need to develop ways of conceptualizing and reconceptualizing. Epistemological mode of 'systems' thinking help such a development to take place in a very effective way.

\section{CONCLUSION}

Criminals and terrorists have very creative and innovative mindsets. It is their actions that are highly misplaced. Security Personnel who have to match or anticipate such actions need to have equally deep levels of creativity and innovation but currently they are constrained in their thinking because of the rules, regulations, laws, policies, procedures, documentation, values, ethics and concern for others. If Security Personnel have to be effective then they need to 'think like a criminal but not act like one'. Doctoral programs that are targeted at the reasoning processes of Security Personnel need to raise the conceptual abilities and capacity of their students. This paper discussed the new paradigm shift that has to be achieved using 'epistemological mode of 'systems' that can achieve the shift.

\section{REFERENCES}

Ackoff, R.L., 1971, Towards a System of Systems concepts, management science, Vol. 17, No. 11

Ackoff, R.L., Emery, E., 1972, On Purposeful Systems, Tavistock Institute, London

Armstrong, H., Jayaratna, N., 2002, Internet Security Management: A Joint Postgraduate Curriculum Design, Journal of IS Education, JISE, Fall Issue, Vol. no. 13, No. 3, 2002

Checkland, P.B., 1981, Systems thinking, Systems Practice, Wiley and Sons, UK

Checkland, P. B., Scholes, J., 1990, 'Soft' Systems Methodology in Action, Wiley and Sons, UK

Churchman, W., 1971, The Design of Enquiring systems, New Basic Books, USA 
Jayaratna, Nimal, 1994, Understanding and evaluating Methodologies, McGraw-Hill, UK

Katz, D., Khan, R. L., 1966, Common Characteristics of Open Systems, Wiley and Sons, UK

Katz, D., Rosenzwig, J. E., 1970, Organisation and Management: A Systems Approach, McGraw-Hill, USA

Vickers, G., 1968, Value systems and Social Processes, Pelican, UK 